\title{
Assessment of the sustainability of economic development under the governments of Russia
}

\author{
Mikhail Savelyev ${ }^{1}$, Natalia Pushina ${ }^{2}$, and Andrey Savchenko ${ }^{1, *}$ \\ ${ }^{1}$ Mitra Association, Pushkinskaya Str. 241, 60, 426008 Izhevsk, Russia \\ ${ }^{2}$ FSBEI HE M.T. Kalashnikov IzhSTU, Studencheskaya Str. 7, 426069 Izhevsk, Russia
}

\begin{abstract}
The article examines the features of the economic development of Russia since 1887 by growth and risk parameters. The development risk was measured using the standard deviation of the annual growth rates of real GDP. Progressive, regressive, conservative, and aggressive development is proposed to determine according to the changes in growth and risk. The authors have analyzed the process of development under individual governments, as well as in general for the imperial, socialist, and post-Soviet periods, with the emphasis in the last two Stalinist and post-Stalinist, liberal and patriotic periods, respectively. Progressive changes in economic development are revealed: Stolypin reforms, industrialization and the "vertical of power"; regressive: civil war, Khrushchev reforms, perestroika, liberalization, and modernization; conservative: Kosygin reforms and "nationalization of the elite". Except for opportunistic growth and risk surges 1911-1913 and 1998-2000, no aggressive developmental periods with identifiable institutional causes were found. The repetitive development cycle of the socialist and postSoviet periods is shown. The conclusion is made about the greater authenticity of the Russian culture of the socialist development model and the least of the liberal ones, as well as the need to develop post-industrial development institutions that are authentic to the Russian culture for their application after the predicted institutional crisis.
\end{abstract}

\section{Introduction}

This research assumes that culture is in different ways consistent with different sociopolitical development models, which may be reflected in macroeconomic indicators. The study of several changes in the socio-economic system in Russia allows us to test this hypothesis. The use of economic growth indicators for these purposes is not informative enough. In this regard, by analogy with the technical analysis of the profitability of securities, the standard deviation of the growth rates of real GDP was used as an indicator of stability.

Such a study is relevant in terms of both the search for the most authentic culture of the Russian development model, and a proof that culture is fundamental to economic

\footnotetext{
${ }^{*}$ Corresponding author: savaisai@gmail.com
} 
development, which we had theoretically substantiated in our previous studies that show the relationship between culture and institutional models [1-3].

A. Madison [4] was one of the first to analyze the results of economic activity over long historical periods. He widely used the methods of quantitative analysis (quantification) as a tool of historical analysis. L.M. Freinkman, V.V. Dashkeeva, M.R. Muftiakhetdinova present in their studies a multifactorial statistical model, which was applied to study fundamental intercountry institutional differences based on various factors: economic, geographic, and cultural-historical [5]. W. Easterly and R. Levin show the formation of modern empirical patterns of economic growth, such as, for example, the growing gap in the levels of GDP per capita between countries, national policies and their impact on longterm economic growth, etc. [6]. Conclusions on the importance of the influence of various factors, including cultural, institutional, on the country's macroeconomic indicators are presented in the works by other authors [7-9]. Akindinova N.V., Bessonov V.A., Iasin E.G., Baranov A.O., Skufiina T.P., and others have studied the analysis of the economic growth of the Russian economy in different historical periods and the factors influencing it [10-12].

In general, we can talk about two main areas of research in this area - a direct analysis of the dynamics of economic growth indicators, as well as the identification and assessment of factors that determine it. No studies on the sustainability of economic development have been identified.

\section{Materials and Methods}

The research object is the Russian economy of 1887-2018. The subject is economic development under individual governments. The research method is a comparative statistical analysis of growth and risk indicators: the growth rate of real GDP and the standard deviation of the same indicator as a characteristic of its stability. Also, the most effective development can be considered as the process with maximum economic growth and minimum risks. If the subsequent period compared to the previous one had a lower risk indicator and a higher growth rate, then such changes in economic development can be considered progressive, the reverse change - regressive. If risks and growth decrease, then such development can be considered conservative; otherwise, the development is aggressive.

\section{Results and Discussion}

As the periods for analysis, the periods of activity of the governments of Russia are chosen with division into three groups by the socio-economic system:

The Imperial period (1887-1913): governments of N.K. Bunge 1887-1895, I.N. Durnovo 1895-1903, S.Iu. Witte 1903-1906, P.A. Stolypin 1906-11, V.N. Kokovtsev 191113. Information base for analysis - Nominal GDP historical series [13]. This source contains data on nominal GDP. For correct comparison, for 1900-1913, the average annual inflation index was calculated and the values of nominal GDP were obtained, reduced by this index, according to the source $[14,17]$. This indicator can be considered the closest analog of real GDP. Actual inflation by years may differ significantly, but for this work, longer periods than a year are studied, and deviations of real GDP from the calculated one due to the deviation of the actual annual inflation index from the average annual level are leveled, which allows us to consider the nominal GDP growth data reduced by the average annual inflation index comparable to real growth.

The Soviet period (1929-1991): governments of V.M. Molotov 1931-41, I.V. Stalin 1941-1953, G.M. Malenkov and N.A. Bulganin 1953-1958, N.S. Khrushchev 1958-1964, 
A.N. Kosygin 1964-1980, N.A. Tikhonov 1980-1985, and N.I. Ryzhkov 1985-1991. Also, within this period, we distinguished the Stalinist period (1931-1958), when the policy of industrialization was pursued, and the post-Stalinist period (1958-1991), when the model of post-industrial development of the socialist economy was not found. The information base for the analysis is Angus Maddison, Historical Statistics of the World Economy [14, 15].

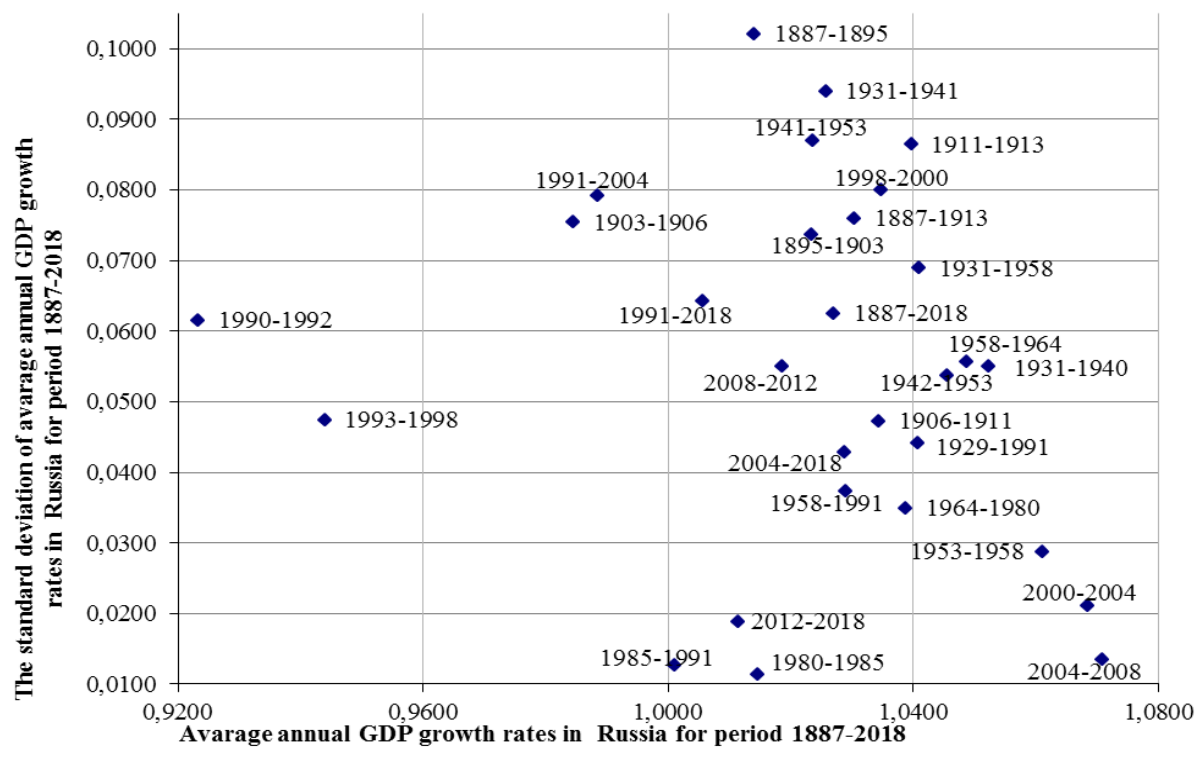

Fig. 1. Analysis of the economic development of Russia during the periods of activity of individual governments in 1887-2018

The Post-Soviet period (1990-2018): governments of I.S. Silaev, B.N. Yeltsin and E.T. Gaidar 1990-1992, V.S. Chernomyrdin 1993-1998, crisis-technical governments of S.V. Kirienko, E.M. Primakov, S.V. Stepashin, V.V. Putin 1998-2000, M.M. Kasyanov 20002004, M.E. Fradkov, and V.A. Zubkov 2004-2008, V.V. Putin 2008-2012, and D.A. Medvedev 2012-2019. Within this period, the liberal (1991-2004) and patriotic periods (2004-2019) are distinguished. The information base for the analysis is the Total Economy Database [16].

No comparable data for earlier periods, the periods of the First World War and the Civil War, and the NEP have been found. Based on the data obtained, the average growth rates and standard deviations were calculated for the periods of government activity; the data are presented in Fig 1.

A comparison of the three main periods clearly shows progressive socialist development in comparison with imperial, and regressive post-Soviet development. At the same time, there is a progressive tendency of development in the Stalinist period only, while the postStalinist period is conservative. The post-Soviet period was more conservative than the imperial period, but the liberal period turned out to be a regression in comparison even with imperial development. The patriotic period is more progressive than the liberal, more conservative than the Stalinist period, and has slightly higher risks than the post-Stalinist period. Thus, the line of effective development in the history of the country runs through the Stalinist and post-Stalinist periods of the socialist era, and the liberal period can be called the indisputable leader of inefficiency.

Speaking about individual governments, the second and last government of the time of Alexander III had the greatest development risks in the studied history of the country, when during the period of crop failure and famine epidemics of typhus and cholera occurred, and 
the economy was not yet sufficiently differentiated and controlled. The worst growth of the imperial period was observed in the economy under the Witte government when there was also a slight increase in risks compared to the period of the Durnovo government. The Stolypin reforms were the country's progressing development, close to the socialist period as a whole. In the times of the Kokovtsev government, the growth of the imperial period reached its maximum but was interrupted by the First World War. It can be assumed that the period of transition from the imperial to the socialist system was a clear regression, and the NEP was symmetrical progress of development, according to the source [13], the real GDP of 1913 was exceeded only in 1929. The transition from NEP to industrialization cannot be assessed unambiguously, as reliable data on the economy under the government of A.I. Rykov are limited to the last two years.

The economy under the governments of Molotov and Stalin showed slightly lower risk and growth than under Bunge and Kokovtsev, respectively, but excluding 1941 from the analysis, which economic catastrophe was due to the well-known military-political events, the pre-war and post-war economic development was more aggressive, than under the Stolypin government and more progressive than during the imperial period as a whole. Under the governments of Malenkov and Bulganin, the socialist economy reached the peak of its progressive development. Khrushchev's reforms were regressive and threw the economy back to the indicators of post-war development. Further development followed a conservative scenario: under the governments of Kosygin and Tikhonov, growth and risk declined.

Perestroika caused a slight regression in development, and, continuing this trend, radical market reforms caused a catastrophe with a long-term economic downturn. Post-crisis aggressive development under four technical governments in 1998-2000 is similar to the war periods. The establishment of the "vertical of power" was progressive, and gave rise to the phenomena of maximum growth and low risks under three subsequent governments. The end of the struggle between oligarchic groups led to the fact that under Putin's second government, the victorious group of managers of state corporations and officials of the financial, economic, and security blocs received their political and economic dividends. The proclaimed policy of "modernization" was a cover for this regression in the country's development. The "nationalization of the elite" under the Medvedev government gave rise to a conservative development comparable to the era of "stagnation"; however, compared to the period of the Fradkov and Zubkov governments, it remained regressive.

\section{Conclusions}

This study does not involve cross-country comparisons, therefore, we cannot speak about the competitiveness of the Russian economy in terms of the indicators identified in the considered periods. An unambiguous conclusion can be made that the institutional model of the Stalinist economy turned out to be the most Russian culture-authentic for long-term advanced development, post-Stalinist - for sustainable development, and the liberal model was the least authentic.

In general, we can note a repeating cycle of development: during a crisis of the ruling elite, elite groups struggle with deep regression (Civil War and Liberal reforms); after the victory of one elite group, progressive development begins (Industrialization and the "Vertical of Power"), superseded by some regression (Economic Councils and Modernization), then conservative development (Stagnation and "Nationalization of the Elite"), and at the end - a new crisis (perestroika). From this point of view, the further development of the current situation in the development of the Russian economy can only have the most negative forecast. This conclusion requires scientists to develop postindustrial and culture-authentic institutions for the development of the Russian economy; 
the main contours of such a solution are outlined in a number of our works [1] for their application after the predicted institutional crisis.

\section{Acknowledgements}

The reported study was funded by RFBR, project number 20-010-00869

\section{References}

1. M.Yu. Savelyev, Multicultural institutionalism: a general economic theory of civilizations. The political economy of traditionalism (2015), http://cognitiofluctus.ru/science/s001/001.htm

2. M.Yu. Savelyev, Bulletin of Udmurt University, Series Economics and Law, 7, 79 (2015)

3. M.Yu. Savelyev, Bulletin of Udmurt University. Series Economics and Law, 7, 135 (2015)

4. A. Maddison, The World Economy: Volume 1: A Millennial Perspective, Volume 2: Historical Statistics (2006)

5. L.M. Freinkman, V.V. Dashkeev, M.R. Muftiakhetdinova, Analysis of institutional dynamics in countries with economies in transition, 252 (2009)

6. W. Easterly, L. Ross, Journal of Monetary Economics, 50(1), 3 (2003)

7. D. Kaufmann, K. Aart, Z.-L. Pablo, Aggregating Governance Indicators, World Bank Research Working Paper, 2195 (1999)

8. D. Kaufmann, K. Aart, Z.-L. Pablo, Governance Indicators, World Bank Research Working Paper, 2196 (1999)

9. A. Helanterä, S.-E. Ollus, Why they, why not we? An analysis of the competitiveness of Finland and Russia, https://iq.hse.ru/

10. T.P. Skufiina, Modern problems of science and education, 5 (2013)

11. A.O. Baranov, ECO, 6, 23 (2012)

12. N.V. Akindinova, V.A. Bessonov, E.G. Iasin, Russian economy: from transformation to development: A report to XX April International Scientific Conference on the Problems of Economic and Social Development, Moscow, April 10-13 (2018)

13. Dincecco, Mark and Mauricio Prado, Nominal GDP Series, 1870-2000, Technical Report, Global Prices and Incomes Database 2013, http://gpih.ucdavis.edu/

14. Angus Maddison, Historical Statistics of the World Economy: 1-2008 AD, http://www.ggdc.net/

15. J. Bolt, J.L. van Zanden, Economic History Review, 67(3), 627 (2014)

16. The Conference Board, Total Economy Database. April 2019, https://www.conferenceboard.org/ 